\title{
Digitalization: Opportunity and Challenge for the Business and Information Systems Engineering Community
}

\author{
Christine Legner • Torsten Eymann • \\ Thomas Hess · Christian Matt · Tilo Böhmann · \\ Paul Drews · Alexander Mädche • Nils Urbach • \\ Frederik Ahlemann
}

Published online: 4 July 2017

(C) Springer Fachmedien Wiesbaden GmbH 2017

\section{Introduction}

The convergence of the so-called SMAC technologies social, mobile, analytics, and cloud computing - has led to an unprecedented wave of digitalization that is currently fueling innovation in business and society. As digitalization is embracing all aspects of our private and professional lives, it is becoming a priority for managers and policymakers, and has made it into the headlines of newspapers, magazines, and practitioner conferences.

This wave of digitalization is creating opportunities for the BISE community to engage in innovative research

Prof. Dr. C. Legner $(\bowtie)$

Faculty of Business and Economics (HEC), University of Lausanne, Internef 127.3, 1015 Lausanne, Switzerland

e-mail: Christine.legner@unil.ch

Prof. Dr. T. Eymann · Prof. Dr. N. Urbach

University of Bayreuth, Universitätsstraße 30, 95447 Bayreuth, Germany

e-mail: Torsten.Eymann@uni-bayreuth.de

Prof. Dr. T. Hess

LMU München, Munich, Germany

Prof. Dr. C. Matt

University of Bern, Bern, Switzerland

Prof. Dr. T. Böhmann

University of Hamburg, Hamburg, Germany

Prof. Dr. P. Drews

Leuphana University of Lüneburg, Lüneburg, Germany

Prof. Dr. A. Mädche

Karlsruhe Institute of Technology (KIT), Karlsruhe, Germany

Prof. Dr. F. Ahlemann

University of Duisburg-Essen, Duisburg, Germany activities and to increase the discipline's visibility. However, since BISE researchers have investigated the increasing exploitation and integration of digital technologies over several decades, they also naturally react with ambivalence when others claim that going digital is a new phenomenon.

\subsection{Clarifying the Basics: Digitalization Versus Digitization}

Before entering the debate, it seems important to clarify the terminological confusion around the phenomenon of digitalization. Although often used interchangeably with digitization (as well as with digital transformation), digitalization should be clearly distinguished from digitization. Digitization is the technical process of converting analog signals into a digital form, and ultimately into binary digits, and is the core idea brought forward by computer scientists since the inception of the first computers (Tilson et al. 2010; Hess 2016). Digitization dematerializes information and decouples information from physical carriers and storage, transmission, and processing equipment. While digitization puts emphasis on digital technologies, the term digitalization has been coined to describe the manifold sociotechnical phenomena and processes of adopting and using these technologies in broader individual, organizational, and societal contexts. With advances in digital technology, we have seen several waves of digitalization that have fundamentally transformed business and society: The first wave focused on technologies replacing paper as physical carrier with computers, leading to higher automation in work routines. The second wave gave birth to the Internet as global communication infrastructure, resulting in changes to the firm's value creation logic and new types of businesses, such as 
e-commerce or intermediaries. Today, we are experiencing the third wave, where the converging SMAC technologies and continuing miniaturization, combined with ever-increasing processing power, storage capacity, and communication bandwidth, has made the vision of ubiquitous computing become very close to reality. As a consequence, digital technologies complement and/or enrich existing products and services and allow building entirely new business models. While digitalization has been the core of the BISE discipline for decades, the current wave transforms almost every aspect of our private and professional environment. It ultimately leads to digital business, life and society and is becoming highly relevant for a large number of stakeholders and disciplines.

\subsection{Digitalization as Opportunity and Challenge}

In the face of a digital revolution, national and regional governments are increasingly defining digitalization as a strategic priority and are setting up large-scale initiatives to foster digital transformation of science, industry, and society. The German Federal Government's Digital Agenda (www.digitale-agenda.de) is a prominent example. In doing so, they increase the public's awareness and introduce new research funding schemes and collaboration models. Digitalization also creates further opportunities to engage in research collaborations with industry. With the omnipresence of digital technologies, companies feel trapped in their traditional ways of working and approach universities more often for innovation projects in research and teaching. They expect students - as digital natives and researchers to provide an outside-in view into digital opportunities in their industries and to help them to innovate and develop digital business models, products and services. Finally, technologies are becoming increasingly user-friendly and accessible to researchers, and cloud services provide low-cost access to very powerful IT infrastructures. Because entry barriers to implementing innovative concepts via prototypes based on the latest technologies are lowering, research ideas and results can be more easily demonstrated. This allows one to make research more tangible, to test and collect feedback on research ideas, to evaluate research prototypes with larger user communities, and to close the gap between research, product development and commercialization.

Notwithstanding the increasing interest in digital technologies and their relevance for individuals, businesses, and society, we observe ambivalence in the BISE community towards digitalization. As a discipline, we have been studying the exploitation and uses of digital technologies for decades - from early mainframe computers to client server systems and, more recently, the Internet and Web 2.0. Digitalization can be considered as the common denominator of our discipline, rather than a completely new phenomenon. Even though the exploitation of digital technology is at the core of our own discipline, many other research communities are swiftly embracing digitalization, often ignoring prior theories, concepts, or approaches from our field. This also raises questions about cross-disciplinary research collaboration and the roles of BISE contributions in these aspects.

\subsection{Reflections on BISE's Role in Digitalization}

In this discussion section, we seek to initiate reflection on how the BISE community can leverage the opportunities and can develop and/or maintain thought leadership on digitalization. We summarize the contributions and subsequent discussions of a panel at the Business and Information Systems Engineering Multi-Conference 2016 (MKWI) in Ilmenau, Germany. This section is meant as a first step in a sequence of discussion sections that summarize debates from panels at subsequent BISE conferences. These will address and further detail specific aspects, such as the evolution of BISE as academic discipline (information management vs. digital transformation), the implications for future workplaces, and the role of corporate IT departments and engagement with emerging with other stakeholders.

In this first discussion section, BISE researchers convey their perspectives on the current wave of digitalization. They shed light on the following questions:

- What are the characteristics of the current wave of digitalization? How does it differ from the previous ones?

- What challenges and opportunities does digitalization bring to the BISE community?

- What novel approaches and research designs do BISE researchers engage into leverage the research opportunities of increasing digitalization?

Prof. Dr. Christine Legner, HEC, University of Lausanne Prof. Dr. Torsten Eymann, University of Bayreuth

\section{Riding the Digital Transformation Wave}

Digitalization has been a topic for information systems research for decades. However, the current wave of digitalization is different: it is driven by $u s$. As Brenner et al. (2014) argue, the power in IT is shifting to users. As users, consumers, and citizens, we expect sophisticated digital services and products. These increasing expectations put pressure on leaders in commercial and public organizations, and create significant opportunities for disruptive startups. Digitalization is enabled by the convergence of 
the so-called IT megatrends (social, mobile, big data, cloud, smart). However, the current wave also pushes traditional topics such as automation and integration forward.

Moving towards digitalized business requires organizations to undergo a massive socio-technical transformation that affects organizational structures, strategies, IT architectures, methods, and business models. In our study on digital excellence (Böhmann et al. 2015), we identified 10 key areas that are subject to this substantive transformation when companies seek to go digital:

- Digital leadership and digital empowerment Employees, management, and top management must update their digital skills sets so as to be able to contribute to digital innovation and transformation.

- Data-driven agility Digitally excellent companies continuously improve their digital services by implementing a build-measure-learn approach. This requires new modes of leadership and organization, improved analytics capabilities, and agile IT.

- Customer and partner engagement Customers and partners are the source of digitalization pressure. They must be actively involved in many processes, since they are a major source of value generation. Digital channels must be optimized and combined appropriately with offline channels.

- Digital platform management In many industries, digital platforms are emerging that are rapidly transforming existing value networks. Companies must understand whether to transform into a platform provider or to participate in platforms that are relevant to their products and services.

- Business model innovation Enterprises are seeking to leverage IT for business model innovation. For this, they must establish creative autonomy for designing and realizing novel business models.

- IT architecture transformation Making the existing IT architecture ready for the challenges of a customerdriven and user-driven IT remains a major challenge for many companies (e.g. in the financial service sector).

- Process digitization and automation In many industries, companies are still seeking to increase the levels of digitization and automation in their processes. This is often a prerequisite for enabling digital services and new business models.

- Digital security and compliance By raising the level of digital interaction level in their ecosystem, enterprises are increasingly exposed to cyber-threats and must take appropriate countermeasures to ensure security.

BISE research has a strong tradition of analyzing and designing sociotechnical systems. For mastering the current digitalization wave, knowledge from BISE research remains relevant. But, like businesses that were not born into the customer-centric digital world, BISE research must understand that digitalization also calls into question established enterprise-centric thinking. A case in point is the emergence of fast IT or digital IT units in companies with new organization model that challenge our knowledge on, among others, IT governance and business-IT alignment (Horlach et al. 2016).

Further, the current wave of digitalization reinforces the need for transdisciplinary research. There are vast opportunities to engage with different communities. A usercentric and data-driven focus provides avenues for cooperating with computer science researchers in software engineering or human-computer interaction (e.g., Maalej et al. 2016). On the business side, opportunities are arising for closer collaboration with service research and marketing (e.g., Lush and Nambisan 2015). The BISE community seems to be fairly well prepared for this challenge, since interdisciplinary and transdisciplinary research projects form part of its research history.

Should the BISE research community embrace digitalization? We argue that it should, based on ambition or anxiety, or both. Ambition would seek substantial and impactful contributions from BISE research that address key challenges of digitalization. Ambition is good, but the stakes are high. Unfortunately, the heart of many developments in the current wave of digitalization don't beat on campus. The digital economy has created ample opportunities for continuous experimentation with new digital business models and services. The models, methods, and tools required for designing and managing digital business are often developed in these companies. Keeping up with the pace of hundreds of thousands of smart people in leading organizations and a vibrant startup community will remain a challenge for BISE researchers. For us, creating impact calls for engaged scholarship beyond campus limits. Thus, for this ride, an intensive exchange of ideas and cooperation with practice in inevitable. Yet IS researchers have another motive to engage in digitalization: anxiety. If we wish to provide relevant education to our current and future students, we should work hard or face being left behind with our legacy approaches of enterprise-centric IT. We must understand how this emerging digital environment works so that we can provide our students with useful models, methods, and technical skills for customer-centric and service-centric information systems. For us, this is all the more reason to engage with digitalization and reflexive practitioners who are addressing these topics.

Prof. Paul Drews, Leuphana University of Lüneburg Prof. Dr. Tilo Böhmann, University of Hamburg 


\section{From CIO to CEO: Digital Transformation as an Opportunity for BISE}

\subsection{What is Digital Transformation?}

Digital transformation describes the changes imposed by information technologies (IT) as a means to (partly) automatize tasks (Hess 2016). Digital transformation is evident in numerous societal areas. For instance, we are already seeing substantial IT-induced changes in political decision-making, judicial frameworks, and related to supply and demand in labor markets. Further, our daily lives and habits are increasingly supported by IT. In business, digital transformation has particular importance, since it requires and enables companies to transact in changing markets.

Against this background, we distinguish three aspects to digital transformation. First, the results of digital transformation (e.g., a novel CRM approach or a novel online service from an insurance company). This relates to a company's target after digital transformation has been carried out. Second, the de facto processes of the transformation, i.e. the necessary changes in a company. For such implementation, suitable incentives or even new roles might be needed. Third, the digital transformation's underlying technological background. In our example of the novel CRM approach, this relates to the CRM system and the online capabilities that are added to the insurer's IT systems, as well as their integration into the company's entire IT landscape.

\subsection{Why Should BISE Take Care of It?}

Besides BISE, several other disciplines (such as marketing or organization studies) could research digital transformation; some already do. We see three main arguments for BISE to take the lead.

BISE's close proximity to technological developments: This is necessary to identify and filter the most promising technological evolutions that can support and shape further digital transformation. This closely relates to firms' uncertainties over which technologies have the potential to substantially impact their business, knowing that many of them might never see successful diffusion in the market.

A realistic view of the technological requirements: Even today, despite much technological progress, not everything that is beneficial for a firm can be realized technologically. Profound technological knowledge is needed even for a first assessment of the likelihood of the successful realization of new IT systems and their integration into existing IT landscapes.

The ability to conduct a comprehensive analysis of the topic: Since digital transformation affects companies in their entirety, it is a matter of great technological, economic, and social relevance. BISE's existing knowledge in these domains and its close proximity to these fields enables comprehensive assessments, which are essential for the organizational design of transformation processes and the definition of a digitization strategy (Matt et al. 2015).

For the reasons given above, in our view, BISE has substantial advantages over other disciplines in addressing digital transformation and potentially making it a success story for which the discipline can become well known.

\subsection{What are the Opportunities for the Positioning of BISE?}

Traditionally, BISE has a strong focus on topics relating to corporate IT departments, since this is where the development of new corporate IT systems and their IT landscapes take place. At the same time, CIOs and their teams are often - besides suppliers of IT products and services the most important contact for BI researchers in companies.

As a topic for BISE, digital transformation opens new possibilities to engage with other important contact persons in firms outside their IT departments. While this has regularly been claimed in the context of discussions on IT's strategic value in firms, it is seldom achieved. First evidence from practice reveals that digital transformation endeavors are often directly supported by CEOs, while some firms employ dedicated Chief Digital Officers (CDOs) (Horlacher 2016) to foster digital transformation. These key C-level executives are useful contacts for BISE researchers, and enable new opportunities for the entire community, such as the establishment of new research programs in cooperation with practice, and the enrichment of new, existing study courses.

Take the media industry as an example, since it's one of the first industries to have been substantially impacted and even threatened by digital transformation over the past 15 years - a process that is ongoing. More than five years ago, several BISE chairs established the Internet Business Cluster (IBC) (http://ibc-muenchen.com) in cooperation with leading media industry partners in the Munich area. Among others, the IBC addresses topics such as digital business models in the media industry and the design and implementation of digitization strategies. The IBC has enjoyed substantial support from partner experts in corporate development, product development, and operations. To support these efforts, LMU Munich has established the new Master's program Media, Management and Digital Technologies (www.mmt.bwl.uni-muenchen.de). This program primarily targets students with a strong interest in the digital transformation of media companies, as well as the foundation and management of startup companies. Both 
approaches require profound business and management expertise combined with solid technological depth.

\subsection{What must Change in BISE?}

Clearly, BISE has always dealt with the creation and design of application systems as well as their integration into the corporate IT landscape. Here, there has typically been a strong focus on the systems, but less on business aspects behind these systems. This is also true for our CRM example: BISE has discussed, in depth, key aspects of functional and technological design of CRM systems, as well as their benefits for users. These are all important aspects and undoubtedly essential for de facto adoption and usage of a company's system. However, digital transformation requires a focus on the business solution first (i.e., the novel CRM approach); based on this, the foundations for the technological system background should be laid, rather than vice versa.

Prof. Dr. Thomas Hess, LMU München Prof. Dr. Christian Matt, University of Bern

\section{BISE's Role in Digital Transformation: Driving Interdisciplinary Research and Innovation}

The hype about digital transformation has put information technology (IT) and information systems (IS) in a much more visible position in business and society than in the past. IT/IS has primarily been considered an enabler of automation, contributing to efficiency increases. Beyond this, the potential of IT/IS to increase effectiveness in businesses by driving vertical data integration as well as improving communication and collaboration by following a people-centric integration approach has been recognized. However, IT/IS is still considered as a basic support function that does not touch or influence the core products and services.

Recently, the potential of IT/IS to complement and/or enrich existing products and services or to build entirely new business models has been recognized. We have also seen that IT/IS significantly influences the ways we live and act in our private lives. The rapid growth of computing power and storage capacity, in combination with advanced software technologies, has enabled many technological innovations, for instance the Internet (of Things) and big data analytics.

Building on these technological innovations, IT/IS has become part of almost every product or service. This has impacted basically every industry sector, ranging from autonomous cars in the automotive domain to robo-advisors in financial services. Further, entire societies are impacted, for instance IT-based social networks are considered an important enabler of the Arab Spring.

However, all these innovations are accompanied by challenges: Extensive IT/IS usage can negatively impact on individual users; issues such as technostress, addictive behaviors, or privacy loss are seeing intensive discussion. Beyond individual-level impacts, digital transformation is also changing the ways people interact in the global village, and IT/IS misuse can also have profound negative consequences. Finally, laws established and defined for an analog world no longer fit the digital world. These limitations are recognized by some enterprises and are leveraged to implement unfair digital business models.

The BISE community's background and the roots make it a potentially highly relevant contributor to address the challenges and to leverage the potentials of digital businesses and society. The community has demonstrated its interdisciplinary ability to speak the languages of different disciplines and to translate between them. Further, understanding the foundations and impacts of IT/IS as well as designing innovative IT/IS solutions were always considered as two - complementary - sides of the same coin. The ability to work at the intersection of and to interlink the social sciences, engineering sciences, and natural sciences is becoming even more critical now. The members of the BISE community have these competencies and should actively contribute to designing digital transformation in business and society.

The research alliance ForDigital (www.fordigital.org), a regional research cluster between the Karlsruhe Institute of Technology (KIT) and the University of Mannheim as well as associated research institutes is an example of an initiative driven by BISE community members. This network brings together researchers from different disciplines such as business, computer science, economics, law, philosophy, psychology, and sociology from the two universities to work together to better understand the phenomenon of digitalization and to design new IT/IS solutions. Thus, we want new theoretical contributions and technological innovations to proactively interplay and inform one another.

The hype about digital transformation offers the BISE community many opportunities. The following key activities and priorities are suggested:

- First, we should develop a leadership position by setting up interdisciplinary programs in digital transformation research. We should contribute to journals beyond our core field and should contribute to our disciplines with our key competencies.

- Second, from an education perspective, we need to position our education offerings (basically, the WI programs) as the ideal preparation for young people to 
become digital transformation leaders. It is also important to export our education offerings and to contribute to education in engineering and the social sciences.

- Third, from an innovation perspective, we should not only talk about digital transformation, but should also do it, for instance in the form of innovative showcases in business and society.

- Finally, we need to ensure that we act as trusted partners to government, to support and contribute to critical societal decision-making.

In our view, the BISE community is in a unique position to lead digital transformation from an academic perspective and to significantly impact business and society with its research and education contributions.

Prof. Dr. Alexander Maedche Karlsruhe Institute of Technology (KIT)

\section{IT Management in the Digital Age: The IT Function's Changing Role in the Focus of BISE Research}

The current digitalization wave is making significant impacts on the corporate world. Digital technologies such as social media, big data, the Internet of Things, mobile computing, and cloud computing significantly influence processes, products, services, and business models, for instance by connecting machines, things, and individuals, as well as by enabling new work, collaboration, and automation models. At first sight, this might not be too new for a community that has been working on innovative computer-based solutions for business for decades, but the IT usage quality has changed dramatically: We are experiencing a massive extension of the scope of business-related IT usage. We used to think of IT as a means to automate or - at best - redesign business processes in the narrow domain of an organization. Today, business IT manifests through cloud-connected toys in the child's room, turbines in power plants with thousands of sensors that create terabytes of data per day, next generation vehicles, smart homes, or consumer apps on smartphones. It would be too short-sighted to think of these systems as only technical artifacts with a user. Instead they are often part of large-scale socio-technical systems that involve larger parts of the society and are based on huge platforms and ecosystems. For companies, this development often poses a significant challenge. Companies that seek to succeed in the changing competitive environment that results from this development must unfold the potentials of digital technologies, rethink their business models for the digital age, and transform. Accordingly, we see three key fields of action for companies developing into digital enterprises:
- Understanding and mastering the disruptive potential of digital technologies refers to the monitoring and analysis of upcoming and maturing technologies. It also includes developing the competencies to utilize these technologies to realize business.

- Developing and managing digital business refers to the realization of new business models enabled by digital technologies and that disrupt traditional business. It often results from the smart fusion of the physical and digital world. Data-driven services, smart products, product-service hybrids, and digital platforms are examples for new business opportunities in the digital age. Developing working business models implies that companies understand the effects of digital transformation at the individual, organizational, competitive, and increasingly societal levels.

- Digital transformation is the technology-induced change caused by digital business. It embraces the necessary goal-oriented organizational, process, and technological transformation necessary for organizations to succeed in the digital age. Digital transformation requires organizations to understand how business models can be implemented and how digitalization changes how organizations are managed.

Although digitalization affects whole companies, we observe that particularly CIOs and IT managers are uncertain about how to cope with the challenges of digitalization. Owing to its inherent technology focus, the current wave of digitalization has increased the importance of IT and heightened the demands on corporate IT functions. Thus, besides ensuring regular IT operations, IT functions are increasingly asked to proactively identify technological innovations, to rapidly transfer them into marketable solutions, and to directly contribute to the company's overall success. Many IT functions, however, do not have the necessary structures, processes and abilities in place to systematically develop business innovations. Additionally, they are often perceived as being too bureaucratic, inflexible and not on par with the business departments (Urbach and Ahlemann 2016).

Considering the historical development of corporate IT, it is not surprising that many IT functions are currently not optimally set up for the challenges of the digital age. Corporate IT has undergone several developments since its inception. Initially, corporate IT focused on operating mainframe computers, and then on the management of increasingly interlinked personal computing. In the mid1990s, the IT industrialization era began with the aim to enhance the efficiency of the IT function and to position it as an internal service provider (Zarnekow and Brenner 2005). Consequently, in many companies the IT function now operates 'far away' from the business, so that both 
effective business-IT-alignment and business innovation have turned out to be continuous challenges.

To meet the challenges of digitization, the IT function must undergo a change that comprises new modes of internal organization as well as new forms of collaboration and alignment with business departments. Concepts like co-location, cross-functional digital teams, IT innovation management and enterprise architecture management can be understood as precursors of the 'new IT function', which switches IT from the role of service provider to those of a consultant, enabler, and innovator. Moreover, developments like cloud computing simplify the outsourcing of elements of the IT value chain. These developments cause a gradual transition of roles and capabilities of today's IT functions and it is to be expected that they will also manifest in new structures, processes, methods, and governance mechanisms.

We see three key requirements for a modern IT function in the digital age. First, the innovation capability must be improved to be able to better react to dynamic market developments. This includes, for example, continuous planning and flexible budgeting processes as well as customer-centric collaboration and innovation management approaches. Second, the IT function should shift its focus from development and operations to user-oriented design capabilities for innovative software solutions. These design activities should be organized around the customer requirements rather than technological factors. Third, we see a need for an improved transformation capability to drive the required changes to the organization. To successfully implement digital business innovations, the organization as a whole must be developed in terms of structure and processes.

These developments require a new setup for the IT function. For that purpose, we propose the innovative-design-transform paradigm as opposed to the plan-build-run approach of the past (Koch et al. 2016):

- Innovate Develop innovative products, services, and business models with the business departments. Key question: What can the IT function do to achieve business innovations and success?

- Design Effective and efficient design of innovative and user-centric solutions (does not necessarily include software development). Key question: How must solutions look like and function to be leading-edge in the market?

- Transform Swift yet sustainable reorganization of business and IT departments in a way that innovations are implemented and accepted. Key question: Which organizational setup is suitable to position innovative products and services in the competitive environment?

In our view, the BISE research community is well-positioned to play a key role in digitalization and digital transformation. Owing to its long history as well as successful basic and applied research revolving around the business use of IT, this discipline is probably best suited to tackle the challenges of digitalization. However, this will require a significant "updating" of our teaching and research. In teaching, we need to carefully revise our curricula to include knowledge and methods required for mastering digitalization. In research, we need to accept that digitalization requires more interdisciplinary research, which not only includes our neighboring disciplines computer science and business administration, but increasingly fields like psychology, sociology, engineering, or even philosophy. We should also rediscover old virtues such as collaborating with innovative firms and should leave unproductive publication game behind us. Only through reflective, relevant and impactful research will we be able to position our discipline as a thought-leader for digitalization.

Prof. Dr. Nils Urbach

University of Bayreuth

Prof. Dr. Frederik Ahlemann

University of Duisburg-Essen

\section{References}

Böhmann T, Drews P, Meyer-Blankart C (2015) Digitale Exzellenz: Eine Bestandsaufnahme zur Digitalisierung deutscher Unternehmen und Behörden. Research Report, Universität Hamburg. https://www.soprasteria.de/docs/librariesprovider33/Studien/digi tale-exzellenz-2015-sopra-steria-consulting.pdf?sfvrsn=8. Accessed 6 June 2017

Brenner W et al (2014) User, use \& utility research: the digital user as new design perspective in business and information systems engineering. Bus Inf Syst Eng 6(1):55-61

Hess T (2016) Digitalisierung. In: Gronau N, Becker J, Leimeister JM, Sinz E, Suhl L (eds): Enzyklopädie der Wirtschaftsinformatik - Online-Lexikon, Ninth edition. GITO, Berlin. http:// www.enzyklopaedie-der-wirtschaftsinformatik.de. Accessed 20 Mar 2017

Horlach B, Drews P, Schirmer I (2016) Bimodal IT: business-IT alignment in the age of digital transformation. In: Nissen $\mathrm{V}$ et al (eds) Multikonferenz Wirtschaftsinformatik (MKWI) 2016. Universitätsverlag Ilmenau, Ilmenau, pp 1417-1428

Horlacher A (2016) Co-creating value - the dyadic CDO-CIO relationship during the digital transformation. In: Proceedings of the 24th European conference on information systems (ECIS), Istanbul

Koch P, Ahlemann F, Urbach N (2016) Die innovative IT-Organisation in der digitalen Transformation. In: Helmke S, Uebel M (eds) Managementorientiertes IT-Controlling und IT-Governance, 2nd edn. Springer, Heidelberg, pp 177-196

Lush RF, Nambisan S (2015) Service innovation: a service-dominant logic perspective. MIS Q 39(1):155-171

Maalej W et al (2016) Towards data-driven requirements engineering. IEEE Softw 33(1):48-54

Matt C, Hess T, Benlian A (2015) Digital transformation strategies. Bus Inf Syst Eng 57(5):339-343 
Tilson D, Lyytinen K, Sørensen C (2010) Digital infrastructures: the missing IS research agenda. Inf Syst Res 21(4):748-759

Urbach N, Ahlemann F (2016) IT-Management im Zeitalter der Digitalisierung - Auf dem Weg zur IT-Organisation der Zukunft. Springer, Heidelberg
Zarnekow R, Brenner WUP (2005) Integriertes Informationsmanagement - Strategien und Lösungen für das Management von ITDienstleistungen. Springer, Heidelberg 